American Journal of Environmental Sciences 6 (1): 20-25, 2010

ISSN 1553-345X

(C) 2010 Science Publications

\title{
Evaluating Plant Species Diversity and Physiographical Factors in Natural Broad Leaf Forest
}

\author{
Seyed Armin Hashemi \\ Department of Forestry, Faculty of Natural Resources, Lahijan Branch, \\ Islamic Azad University, Iran
}

\begin{abstract}
Problem statement: Species diversity is one of the most important specifications of biological societies. Diversity of organisms, measurement of variety and examination of those hypotheses that are about reasons of diversity are such as affairs that have been desired by the ecologists for a long time. Approach: In this research, diversity of plant species in forest region, numbers of 60 sample plots in $256.00 \mathrm{~m}^{-2}$ had been considered in random-systematic inventory was considered. In each sample plot, four micro-plots in $2.25 \mathrm{~m}^{-2}$ in order to study on herbal cover, were executed that totally 240 micro-plots were considered. At each plot six diversity indices in relation to physiographic factors (slope, geographical aspect and altitude from the sea level) were studied. Results: The results indicated that species diversity is more in the northern aspect and also species diversity in slops less than $30 \%$ has the most amounts. Factor of altitude from the sea level did not have meaningful relation with species diversity. Conclusion: Through study on correlation of the numbers of species in sample plots with indices and also process and role of indices in different processors of analysis, Simpson's reciprocal index was suggested as suitable index in this type of studies.
\end{abstract}

Key words: Physiographical factors, diversity, forest, Simpson's index, slope, aspect, altitude

\section{INTRODUCTION}

Physiographic is abbreviation of Physical Geography that has many effects on plant diversity and their variance (Barnes et al., 1998). Different researches have considered the biodiversity through considering to physiographic (Baker and Barnes, 1998) or slope or aspect or combining two slope and aspect factors (Sternberg and Shoshany, 2001). Biodiversity has so wide meaning and consists of genetic diversity up to ecosystems diversity. Species diversity is known equal to biodiversity that is limited to diversity in local or regional surface (Krebs, 1998). Species diversity is one of the important specifications of bio-societies that are measured in different ways (Krebs, 1998). Diversity of organisms, measurement of diversity and examination of some hypothesis about reasons of diversity are some cases that have been favored by ecologists for a long time (Barnes et al., 1998). Researchers have applied different indices in order to measurement of diversity (Krebs, 1998).Understanding of necessity of species diversity that has happened recently has caused to concentrate on the quality of measurement of biodiversity in plants and animals a lot (Ehrlich and Wilson, 1991). In most studies about biodiversity,
Alpha and Beta diversities have been considered (Pitkanen, 1998). Alpha diversity has been species diversity in a region (Whittaker, 1972) and Beta diversity mentions to the amount of changes of species in environmental gradient length (Whittaker, 1972; Wilson and Shmida, 1984). The first index of heterogeneity has been applied by Simpson in the year 1949 for the first time (Whittaker, 1972) and many copies of this index have been developed up to now. Another index that has wide application in studies is Shannon index (Vujnovic et al., 2002). Beside to the indices related to Alpha diversity; different methods have been developed for measurement the evenness (Pitkanen, 1998). Evenness has been considered as a fundamental fact in the habitat with more than one species (Molinari, 1989). In fact, evenness indices are indicatives of amount of abundance of species in a society. The first evenness index was developed by Hill (1973) that it made possible the quantity comparison of the gained results from the different habitats (Pitkanen, 1998). Then Alatalo (1981) and Molinari (1989) established the measurement of Evenness based on Hill method. Molinari developed his method because two defects of F Index, one of them, evaluation more than reality and the other one, having non-linear 
correlation. In the present article, Alpha diversity has been studied and important indices of species diversity and evenness were calculated.

Main objective of this research in the first process is measurement of diversity based on different indices and analysis of these indices based on different classification and in second process, study on status of different indices in producing of distinguish between classes and evaluation of indices.

\section{MATERIALS AND METHODS}

The study case region: The study case region is the forest of Guilan province. Study case Habitat with area: 47 ha has been located. Status of raining in these regions is in snowing aspect, more. $44.9 \%$ of raining is in winter, $29.50 \%$ in autumn, $25.50 \%$ in spring and only $0.1 \%$ in summer. Average of annual raining is $590.50 \mathrm{~mm}$, average of annual heat degree is $13.1^{\circ} \mathrm{C}$ and average of annual relative humidity is $45.1 \%$. Climate of the region is cold semi-humid.

Method: Numbers of 60 sample plots in $256.00 \mathrm{~m}^{2}$ have been considered in random-systematic inventory was considered. In each sample plot, four micro-plots in $2.25 \mathrm{~m}^{2}$ in order to study on herbal cover, were executed that totally 240 micro-plots were considered. In plot of the main samples of species, number and percentage of the trees and shrubs cover (through measurement of small crown and big crown diameters) were noted. In the micro-plots, species, number and percentage of herbal species were registered, too. Number of sample plot was determined through calculation of changes coefficient and acceptable error of sampling (Barbour et al., 1999). Area of sample plots was gained through drawing of species surface curve (Cain, 1938) for herbal, tree and shrub cover in separate aspect, too. The maps of slope, aspect and altitude from the sea level were prepared (Fig. 1-3). Slope of the region was divided into three floors: Gently sloping (less than 30\%), average sloping (30-60\%) and high slopping (more than 60\%) and the altitude was divided into four floors and geographical aspect was divided into the main aspects.

Assessment of the diversity in Alpha surface for the region using the most important indices of diversity (Alatalo, 1981) in two sections of species richness and evenness was fulfilled. Calculated indices have been mentioned in Table 1.

Statistical methods: At first, following of the main and changed data of the normal distribution were studied by Kolmogorov-Smirnov Test and being homogenous of variances by loan Test and the best data distribution was selected for data analysis. In order to study on difference or not-difference of slop floors, aspect and altitude from the sea surface, on the basis of each one diversity indices with consideration to normal and homogenous being of data, Analysis Of Variance (One Way-ANOVA) (Cannon et al., 1998; Vujnovic et al., 2002; Sagar et al., 2003) was used. After being meaningful of the indices differences in different floors, for multiple comparing of averages, Duncan Test was used (Pitkanen, 1998).

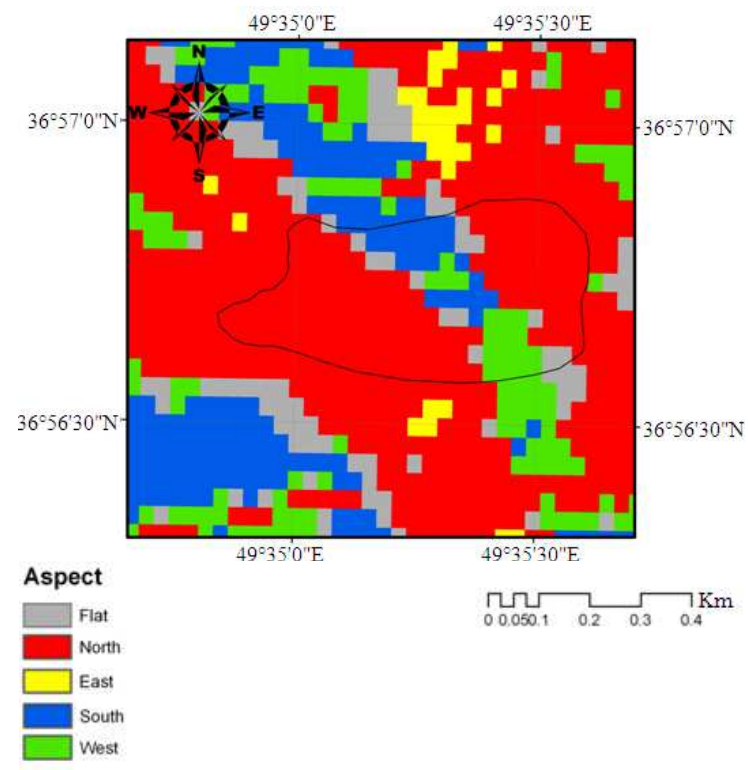

Fig. 1: Map on geographical aspects of study region

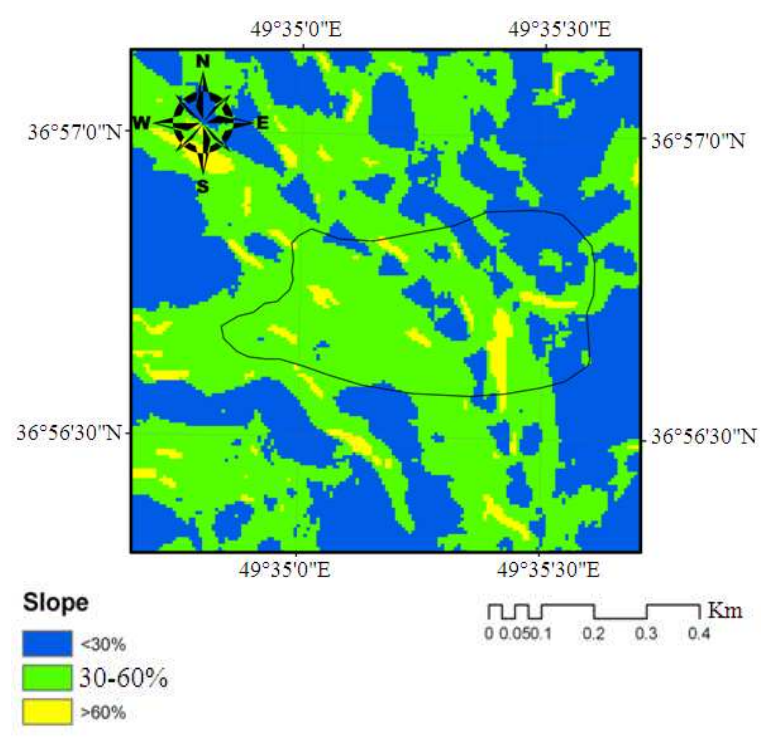

Fig. 2: Map on floors of slope in study region 
Am. J. Environ. Sci., $6(1): 20-25,2010$

Table 1: Used indices of evenness and diversity

\begin{tabular}{|c|c|c|}
\hline Indices & References & Equation \\
\hline \multicolumn{3}{|l|}{ Diversity indices alpha } \\
\hline Shannon's $\left(\mathrm{H}^{1}\right)$ & Peet (1974) & $\mathrm{H}^{\prime}=-\sum_{\mathrm{i}=1}^{\mathrm{s}} \mathrm{p}_{\mathrm{i}} \ln \left(\mathrm{p}_{\mathrm{i}}\right)$ \\
\hline Simpson's reciprocal $\left(\mathrm{N}_{2}\right)$ & Hill (1973) & $\mathrm{N}_{2}=\left(\sum_{\mathrm{i}=1}^{\mathrm{S}} \mathrm{p}_{\mathrm{i}}\right)^{-1}$ \\
\hline Hill's $\left(\mathrm{N}^{1}\right)$ & Hill (1973) & $\mathrm{N}_{1}=\exp \left\lfloor-\sum_{\mathrm{i}=1}^{\mathrm{s}} \mathrm{p}_{\mathrm{i}} \ln \left(\mathrm{p}_{\mathrm{i}}\right)\right\rfloor$ \\
\hline \multicolumn{3}{|l|}{ Evenness indices } \\
\hline Pielou’s $\left(J^{\prime}\right)$ & Peet (1974) & $\mathbf{J}^{\prime}=\left[-\sum_{\mathrm{i}=1}^{\mathrm{s}} \mathrm{p}_{\mathrm{i}} \ln \left(\mathrm{p}_{\mathrm{i}}\right)\right] / \mathrm{inS}$ \\
\hline Alatalo's (F) & Alatalo (1981) & $\mathrm{F}=\frac{\left(\mathrm{N}_{2}-1\right)}{\left(\mathrm{N}_{1}-1\right)}$ \\
\hline Molinari's (G) & Molinari (1989) & $\mathrm{G}=\left\lfloor(\arcsin F) / 90^{\circ}\right\rfloor \mathrm{F}$ \\
\hline
\end{tabular}

$\mathrm{n}_{\mathrm{i}}$ : Number of $\mathrm{i}$ species in sample plot spices number $\mathrm{i}$ in sample plot; $\mathrm{S}$ : Total number of species in sample plots; $\mathrm{p}_{\mathrm{i}}$ : A ratio of i species in the society

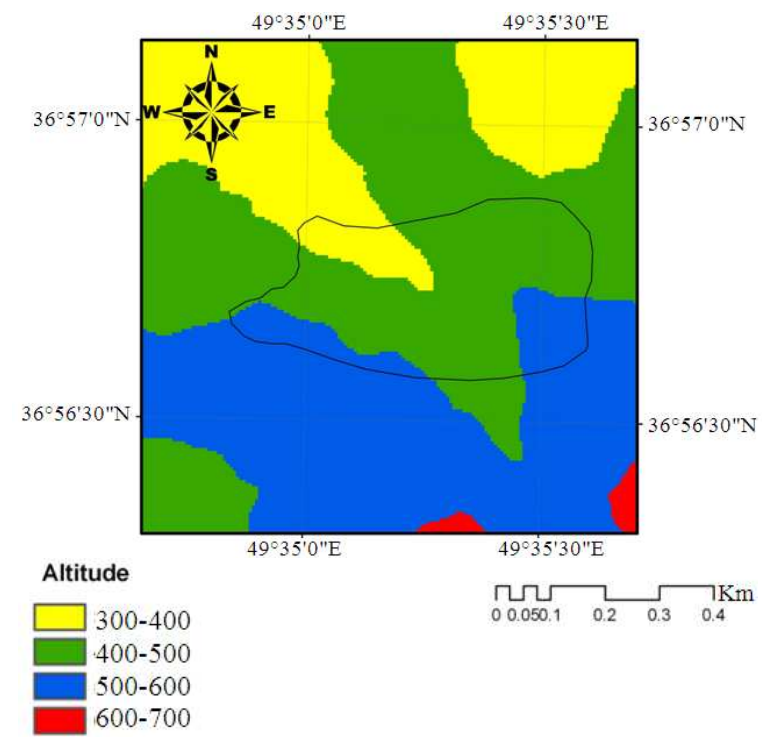

Fig. 3: Map of the altitude from the sea level of study region

In order to study on correlation of variables, Pearson Correlation Coefficient was used. Using the Beers et al. (1966) equation, (Cos (45-A)+1, A shows Azimuth of the domain) geographical aspect were changed in order to be used in analysis.

\section{RESULTS}

Totally, number of 114 plant species, belonging to 76 genus and 31 families were gathered in the region of study case. Leguminosae family and Trifolium genus were the most numbers of species. Results indicate that Bromus tectorum species have been the highest appearance in $96 \%$ of sample plots.

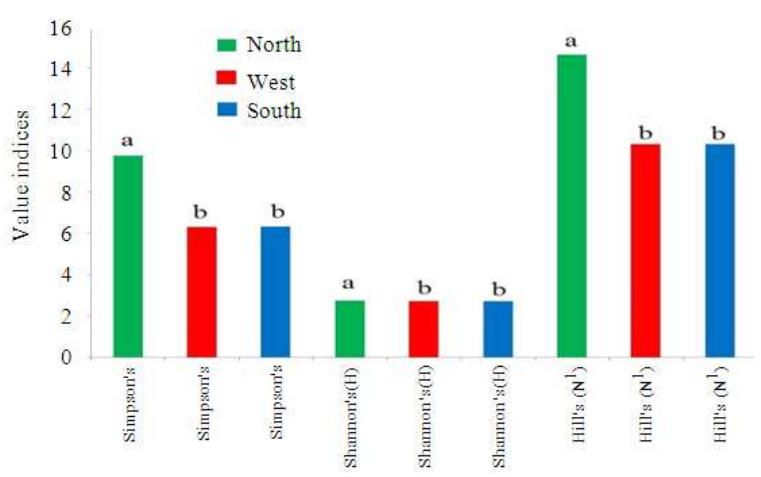

Fig. 4: Average of diversity indices in different aspect

Thereafter, Ziziphora capitata and Torilis leptophyla species with $94 \%$ were registered. Out of tree species, Fagus orientalis in $83 \%$ and Carpinus betulus in $76 \%$ of sample plots have been seen.

Analysis of the physiographical factors: Average, minimum and maximum indices of Alpha diversity have been mentioned in Table 2. Kolmogorov-Smirnov Test indicated that amounts of all indices were normal.

In order to study on the effects of on diversity indices, each one of these factors were classified. General study of the effect of these factors, with consideration to normal being of data was fulfilled by variance of analysis. General study of indices in relation to physiographical factors indicated that factor of altitude, does not have meaningful effect on none of the indices of species diversity but effect of slope was meaningful on all indices except to Alatalo and Molinary indices. Effect of aspect was meaningful on Simpson's reciprocal $\left(\mathrm{N}_{2}\right)$, Shannon's $\left(\mathrm{H}^{1}\right)$, Hill's $\left(\mathrm{N}^{1}\right)$ indices and was not meaningful on Pielou's $\left(\mathrm{J}^{\prime}\right)$ Alatalo's (F), Molinari's (G). Results of Analysis Of Variance (One Way-ANOVA) have been mentioned in Table 3-5. 
Am. J. Environ. Sci., 6 (1): 20-25, 2010

Table 2: Minimum, maximum and average, diversity alpha and evenness indices in study area

\begin{tabular}{|c|c|c|c|c|c|c|}
\hline & \multicolumn{3}{|l|}{ Diversity indices } & \multicolumn{3}{|c|}{ Evenness indices } \\
\hline & Simpson's reciprocal $\left(\mathrm{N}_{2}\right)$ & Shannon's $\left(\mathrm{H}^{1}\right)$ & Hill's $\left(\mathrm{N}^{1}\right)$ & Pielou's $\left(\mathrm{J}^{\prime}\right)$ & Alatalo's (F) & Molinari's (G) \\
\hline Minimum & 2.00 & 2.34 & 3.83 & 0.43 & 0.29 & 0.09 \\
\hline Maximum & 14.00 & 2.97 & 19.84 & 0.89 & 0.78 & 0.70 \\
\hline Average & 7.24 & 2.83 & 11.59 & 0.74 & 0.56 & 0.36 \\
\hline
\end{tabular}

Table 3: Variance of analysis (One-Way ANOVA) of indices in altitude from sea level

\begin{tabular}{lllllll}
\hline & Simpson's reciprocal $\left(\mathrm{N}_{2}\right)$ & Shannon's $\left(\mathrm{H}^{1}\right)$ & Hill's $\left(\mathrm{N}^{1}\right)$ & Pielou's $\left(\mathrm{J}^{\prime}\right)$ & Alatalo's $(\mathrm{F})$ & Molinari's $(\mathrm{G})$ \\
\hline $\mathrm{F}$ & 0.89 & 0.71 & 1.90 & 1.82 & 0.86 & 2.23 \\
$\mathrm{P}$ & $0.42 \mathrm{~ns}$ & $0.55 \mathrm{~ns}$ & $0.67 \mathrm{~ns}$ & $0.18 \mathrm{~ns}$ & $0.47 \mathrm{~ns}$ & $0.14 \mathrm{~ns}$ \\
\hline **: Significant at the $0.01 ; *$ : Significant at the $0.05 ; \mathrm{ns}$ : Non-significant & & &
\end{tabular}

Table 4: Variance of analysis (One-Way ANOVA) of indices in slope floor

\begin{tabular}{lllllll}
\hline & Simpson's reciprocal $\left(\mathrm{N}_{2}\right)$ & Shannon's $\left(\mathrm{H}^{1}\right)$ & Hill's $\left(\mathrm{N}^{1}\right)$ & Pielou's $\left(\mathrm{J}^{\prime}\right)$ & Alatalo's $(\mathrm{F})$ & Molinari's $(\mathrm{G})$ \\
\hline $\mathrm{F}$ & 4.64 & 5.560 & 6.750 & 3.34 & 0.66 & 0.89 \\
$\mathrm{P}$ & $00.1^{* *}$ & $0.006^{* *}$ & $0.002^{* *}$ & $0.04^{*}$ & $0.52 \mathrm{~ns}$ & $0.42 \mathrm{~ns}$ \\
\hline **: Significant at the 0.01; *: Significant at the $0.05 ; \mathrm{ns}$ : Non-significant & & &
\end{tabular}

Table 5: Variance of analysis (One-Way ANOVA) of indices in different aspects classification

\begin{tabular}{lllllll}
\hline & Simpson's reciprocal $\left(\mathrm{N}_{2}\right)$ & Shannon's $\left(\mathrm{H}^{1}\right)$ & Hill's $\left(\mathrm{N}^{1}\right)$ & Pielou's $\left(\mathrm{J}^{\prime}\right)$ & Alatalo's $(\mathrm{F})$ & Molinari's $(\mathrm{G})$ \\
\hline $\mathrm{F}$ & 5.77 & 4.76 & 6.17 & 2.41 & 1.12 & 1.57 \\
$\mathrm{P}$ & $0.005^{* *}$ & $0.01^{* *}$ & $0.004^{*}$ & $0.1 \mathrm{~ns}$ & $0.33 \mathrm{~ns}$ & $0.22 \mathrm{~ns}$ \\
\hline **: Significant at the 0.01 ; *: Significant at the $0.05 ; \mathrm{ns}$ : Non-significant & & &
\end{tabular}

Table 6: Semi-matrix of correlation of diversity indices

\begin{tabular}{|c|c|c|c|c|c|c|}
\hline \multicolumn{2}{|c|}{ Simpson's reciprocal $\left(\mathrm{N}_{2}\right)$} & \multirow[t]{2}{*}{ Shannon's $\left(\mathrm{H}^{1}\right)$} & \multirow[t]{2}{*}{ Hill's $\left(\mathrm{N}^{1}\right)$} & \multirow[t]{2}{*}{ Pielou's $\left(\mathrm{J}^{\prime}\right)$} & \multirow[t]{2}{*}{ Alatalo's (F) } & \multirow[t]{2}{*}{ Molinari's (G) } \\
\hline Simpson's reciprocal $\left(\mathrm{N}_{2}\right)$ & 1.00 & & & & & \\
\hline Shannon's $\left(\mathrm{H}^{1}\right)$ & 0.90 & 1.00 & & & & \\
\hline Hill's $\left(\mathrm{N}^{1}\right)$ & 0.94 & 0.97 & 1.00 & & & \\
\hline Pielou's ( $\left.\mathbf{J}^{\prime}\right)$ & 0.90 & 0.94 & 0.90 & 1.00 & & \\
\hline Alatalo’s (F) & 0.84 & 0.65 & 0.64 & 0.78 & 1.00 & \\
\hline Molinari’s (G) & 0.84 & 0.62 & 0.62 & 0.76 & 0.99 & 1 \\
\hline
\end{tabular}

Table 7: Correlation diversity indices with species number in sample plots, Aspect, (ASL), slope

\begin{tabular}{|c|c|c|c|c|c|c|}
\hline & Simpson's reciprocal $\left(\mathrm{N}_{2}\right)$ & Shannon's $\left(\mathrm{H}^{1}\right)$ & Hill's $\left(\mathrm{N}^{1}\right)$ & Pielou's $\left(J^{\prime}\right)$ & Alatalo's (F) & Molinari's (G) \\
\hline Aspect & $0.01 \mathrm{~ns}$ & $0.03 \mathrm{~ns}$ & $0.02 \mathrm{~ns}$ & $0.06 \mathrm{~ns}$ & $0.02 \mathrm{~ns}$ & $0.03 \mathrm{~ns}$ \\
\hline Slope & $0.32 *$ & $-0.28 *$ & $-0.33 * *$ & $-0.19 n s$ & $-0.16 n s$ & $-0.19 n s$ \\
\hline ASL & $0.09 \mathrm{~ns}$ & $0.06 \mathrm{~ns}$ & $0.03 \mathrm{~ns}$ & $0.15 n$ & $0.20 \mathrm{~ns}$ & $0.18 \mathrm{~ns}$ \\
\hline Number of species & $0.21 \mathrm{~ns}$ & $0.38 * *$ & $0.41 * *$ & $0.09 \mathrm{~ns}$ & $-0.17 \mathrm{~ns}$ & $-0.17 \mathrm{~ns}$ \\
\hline
\end{tabular}

**: Significant at the $0.01 ; *$ : Significant at the 0.05 ; ns: Non-significant

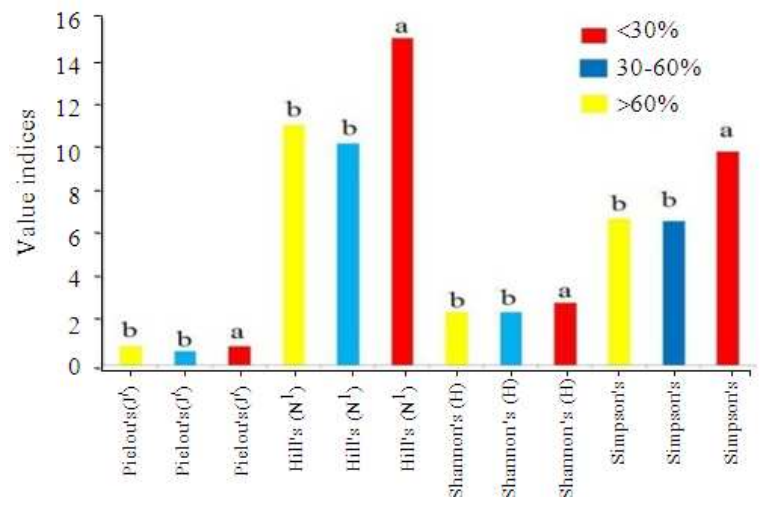

Fig. 5: Average of diversity indices in slope floors
After being meaningful of difference of indices in different aspects and slopes using variance analysis, in order to separate comparing of classifications, Duncan Test was used. The gained results of Duncan Test in different aspects showed that all indices in northern side has meaningful different with western and southern sides and average of these indices in northern side are more than two other sides.

But there were not meaningful difference between indices of two western and southern sides (Fig. 4). On the basis of Simpson's reciprocal $\left(\mathrm{N}_{2}\right)$, Shannon's $\left(\mathrm{H}^{1}\right)$, Hill's $\left(\mathrm{N}^{1}\right)$ indices slopes less than $30 \%$ have more average in comparison with slopes more than $30 \%$. But between $30 \%$ up to $60 \%$ slopes and slopes more than 
$60 \%$, there is not meaningful difference in the view point of three mentioned indices. Average of Pielou's $\left(\mathrm{J}^{\prime}\right)$ index in slope less than $30 \%$ has more amount in comparison with slopes more than $60 \%$. But there is not meaningful difference between slopes $30 \%$ up to $60 \%$ and slopes more than $60 \%$ (Fig. 5).

Analysis of correlation: With consideration to normal being of data, Pearson Correlation Coefficient was used for study on correlation of indices with each other (Table 6), correlation of indices with quantified variable of aspect, slope, altitude from sea level and number of species in sample plots (Table 7).

Results of study on correlation of indices with each other indicates strong correlation, positive and meaningful $(p>0.01)$ among all indices. There is maximum correlation between Alatalo and Molinary indices and minimum correlation between Moliniary and Shannon's $\left(\mathrm{H}^{1}\right)$ indices and Molinary and Hill. Results of study on correlation of diversity indices with number of species in sample plots, aspect, slope and altitude of sea level have been mentioned in Table 7. Two variables of slope and altitude do not have meaningful correlation. But negative and meaningful correlation between simpson's reciprocal $\left(\mathrm{N}_{2}\right)$, Shannon's $\left(\mathrm{H}^{1}\right)$ and Hill indices with slope are seen. Also, Shannon's $\left(\mathrm{H}^{1}\right)$ and Hill indices indicate meaningful and positive correlation with number of species in sample plots. But simpson's reciprocal $\left(\mathrm{N}_{2}\right)$, Pielou's (J'), Alatalo's (F) and Molinari's (G) indices do not have meaningful correlation with number of species in sample plots.

\section{DISCUSSION}

Calculation and comparison of different indices of diversity, as a favorite method is considered for study on biodiversity. All six calculated indices in this study have been mentioned as the most applicable indices (Peet, 1974). Although, altitude from sea level, geographical aspect and slope as effective factors on diversity have been mentioned (Vujnovic et al., 2002) but in the present study, effect of altitude from sea level with diversity was not meaningful. This matter may be because of limited altitude domain of the region. But effect of slope and geographical aspect on species diversity was meaningful. It can be seen that the slope floor less than $30 \%$ has maximum diversity and also relation of slope with some indices has been meaningful and negative effect of slope on species diversity have completely been tangible. Limitation of humidity in the region and negative effect of slope because of water drainage and taking out of plant availability, in addition to clean the foodstuffs may cause to decrease species diversity because of unflavored being of growing conditions. On the basis of the gained results, northern side in the region of study case has more diversity in comparison with the other domains. This matter has been reported by (Sternberg and Shoshany, 2001). This subject may be because of more being of soil humidity for less receiving of solar energy and totally being better of growing conditions in northern domain, too.

\section{CONCLUSION}

Consequently, with consideration to the role of different indices in different analysis and also nonbeing meaningful of the correlation of Simpson index with number of species in sample plots, may suggest this index as a suitable index for applying in such studies. Concluded in assessment of diversity indices for study of plant cover diversity that Simpson index is one of the suitable indices for producing of distinct among different classifications, too (Pitkanen, 1998).

\section{REFRENCES}

Alatalo, R.V., 1981.Problems in the measurement of evenness in ecology. Oikos, 37: 199-204. http://www.jstor.org/pss/3544465

Baker, M.E. and B.V. Barnes, 1998. Landscape ecosystem diversity of river floodlains in northwestern lower Michigan. USA. Can. J. For., 28:1405-1418. DOI: 10.1139/cjfr-28-9-1405

Barbour, M.G., J.H. Burk, W.D. Pitts, F.S. Gilliam and M.W. Schwartz, 1999. Terrestrial Plant Ecology. 3rd Edn., Benjamin Cummings, ISBN: 13: 9780805300048, pp: 649.

Barnes, B.V., D.R. Zak, S.R. Denton and S.H. Spurr, 1998. Forest Ecology. 4th Edn., John Wiley and Sons Inc., ISBN: 13: 978-0471308225, pp: 773.

Beers, T.W., P.E. Dress and L.C. Wensel, 1966. Aspect transformation in site productivity research. J. Forest, $\quad$ 80: 493-498. http://library.eri.nau.edu/gsdl/collect/erilibra/index/ assoc/HASH0103.dir/doc.pdf

Cain S.A., 1938. The species-area curve. Am. Midland Natural, 19: 573-581. http://www.jstor.org/pss/2420468

Cannon, H.C., R.P. Peart and L. Lighton, 1998. Tree species diversity in commercially logged bornean rainforest. Science, 281: 1366-1368. DOI: 10.1126/science.281.5381.1366

Ehrlich, P.R. and E.O. Wilson, 1991. Biodiversity studies: Science and policy. Science, 253:758-762. DOI: $10.1126 /$ science. 253.5021 .758 
Hill, M.O., 1973. Diversity and evenness: A unifying notation and its consequences. Ecology, 54: 427-431. http://www.jstor.org/pss/1934352

Krebs, J.C., 1998. Ecological Methodology. Addison Wesley Longman Inc., ISBN: 13: 9780321021731, pp: 620.

Molinari, J.A., 1989. Calibrated index for the measurement of evenness. Oikos, 56: 319-326. http://www.jstor.org/pss/3565616

Peet, R.K., 1974. The measurement of species diversity. Ann. Rev. Ecol. Syst., 5: 285-307. DOI:10.1146/annurev.es.05.110174.001441

Pitkanen, S., 1998. The use of diversity indices to assess the diversity of vegetation in managed boreal forests. For. Ecol. Manage., 112: 121-137. DOI: $10.1016 / \mathrm{S} 0378-1127(98) 00319-3$

Sagar, R., A.S. Raghubanshi and J.S. Singh, 2003.Tree species composition, dispersion and diversity along a disturbance gradient in dry tropical forest region of India. For. Ecol. Manage., 186: 61-71. DOI: 10.1016/S0378-1127(03)00235-4
Sternberg, M. and M. Shoshany, 2001. Influence of slope aspect on Mediterranean woody formation: Comparison of semiarid and an arid site in Israel. Ecol. Res., 16: 335-345. DOI: 10.1046/j.14401703.2001.00393.x

Vujnovic, K., R.W. Wein and M.R.T. Dale, 2002. Predicting plant species diversity in response to disturbance magnitude in grassland remnants of central Alberta. Can. J. Botany, 80: 504-511. DOI: 10.1139/b02-032

Whittaker, R.H., 1972. Evolution and measurement of species diversity. Taxon, 21: 213-251. DOI: $10.2307 / 1218190$

Wilson, M.V. and A. Shmida, 1984. Measuring beta diversity with presence- absence data. J. Ecol., 72: 1055-1064.

http://www.jstor.org/stable/2259551 